\title{
Manufacturing Process of Carbon Short Fiber Reinforced Al Matrix With Preformless and Their Properties
}

Yongbum Choi ( $\nabla$ ybchoi@hiroshima-u.ac.jp )

Hiroshima University

\section{Xuan Meng}

Hiroshima University

\section{ZheFeng Xu}

Yanshan University

\section{Research Article}

Keywords: Fiber Reinforced, Vickers hardness

Posted Date: September 3rd, 2021

DOI: https://doi.org/10.21203/rs.3.rs-863005/v1

License: (c) (i) This work is licensed under a Creative Commons Attribution 4.0 International License.

Read Full License

Version of Record: A version of this preprint was published at Scientific Reports on December 1st, 2021. See the published version at https://doi.org/10.1038/s41598-021-02915-7. 


\section{Abstract}

Conventional manufacturing process of fiber reinforced metal matrix composites via liquid infiltration processes, preform manufacturing using inorganic binders is essential. However, the procedure involves binder sintering, which requires high energy and long operating times. A new fabrication process without preform manufacturing is proposed to fabricate carbon short fiber (CSF)-reinforced aluminum matrix composites using a low-pressure infiltration method. To improve the wettability and avoid interfacial reactions in CSF/Al matrix composites, the fibers were plated with copper using electroless plating process. Various volume fractions of CSFs were used to determine optimum fiber content which would produce versatile mechanical and thermal properties. Effect of CSFs content on properties such as Vickers hardness and thermal conductivity was studied. Cu-plated CSFs showed good bonding with the Al matrix and CSFs were randomly dispersed inside the composites, with CSF content of up to 29.1 vol.\%, through the new manufacturing process. It showed better fiber distribution than the composite fabricated perform with $\mathrm{SiO}_{2}$ binder, which was determined by comparing the relative frequency distribution of CSFs in composites. Vickers hardness of the composites showed an obvious improvement over that of the Al matrix, and the hardness increased as the CSF content increased. The Cu-plated CSF (14.3 vol.\%) reinforced Al matrix composite exhibited the highest thermal conductivity $\left(184.1 \mathrm{~W} \cdot \mathrm{m}^{-1} \cdot \mathrm{K}^{-1}\right)$. However, the thermal conductivity decreased as CSF content increased to 29.1 vol.\% due to the defects in composite.

\section{Introduction}

Carbon fiber (CF) is one of the most appealing reinforcements and possesses low density, high tensile strength and high thermal conductivity (TC) (Seo et al. 2009). CF- reinforced aluminum composites combine the properties of $\mathrm{CF}$ and $\mathrm{Al}$, exhibiting low density and excellent mechanical and thermal/electrical properties (Hajjari et al. 2010, Lancin et al. 2000) and are expected to be utilized as heat sink materials. The conventional infiltration processes for fabricating CSF reinforced Al matrix composites generally use inorganic binders such as $\mathrm{SiO}_{2}$ (Meng et al. 2018), $\mathrm{Al}_{2} \mathrm{O}_{3}$ (Zeng et al. 1998), or $\mathrm{TiO}_{2}$ (Clemet et al. 2007) for the CSF preform manufacturing. However, preform manufacturing with an inorganic binder is complicated, and the preform needs high temperatures and more time for binder sintering. Therefore, a novel fabrication process that is cost-effective with high production efficiency without requiring preform manufacturing is needed for manufacturing CSF/Al composites.

In the liquid infiltration process for fabricating CF-reinforced Al matrix composites, problems such as poor wettability between $\mathrm{CF}$ and $\mathrm{Al}$ matrix, and the high reactivity of CFs with $\mathrm{Al}$ and its alloys, forming undesirable interfacial reaction products (e.g., $\mathrm{Al}_{4} \mathrm{C}_{3}$ ), limit the applications of $\mathrm{CF}$ reinforced $\mathrm{Al}$ matrix composites (Rams et al. 2007). To solve these, surface modification of CF is proposed as the most effective way to improve wettability and prevent the formation of interfacial reactions. Copper (Cu) has been proven to be effective as it improves the wettability, thermal conductivity, and impact strength (Urena et al. 2007). The low-pressure infiltration process (LPI) (Choi et al. 2006) has been widely adopted 
for manufacturing composites due to the advantage of requiring relatively simple facilities and being cost-effective.

The objective of this research is to develop a new process for fabricating CSF reinforced Al matrix composites without preform manufacturing. An electroless Cu plating process was conducted on the CSFs to improve wettability. The most suitable electroless Cu plating conditions and infiltration conditions were analyzed. In addition, the effect of CSF content on Vickers hardness and thermal conductivity of composites without preform manufacturing was also investigated.

\section{Experimental Procedure}

A1070 with a purity of $99.7 \%$ was used as the matrix in this experiment. Pitch based CSF (K13D2U, Mitsubishi Plastics, Inc.), with a diameter and aspect ratio of $11 \mu \mathrm{m}$ and 230, respectively, was used as the reinforcement. To skip the preform manufacturing process, electroless Cu-plating was conducted on CSFs for the 30-120s. The $\mathrm{pH}$ and temperature of the electroless plating bath were 12 and $298 \mathrm{~K}$, respectively. The electroless Cu plating process is summarized in Table 1. Cu-plated CSFs were put into a graphite mold of diameter $10 \mathrm{~mm}$ with height adjusted to $10 \mathrm{~mm}$ to control the volume fraction of $\mathrm{CF}$, the A1070 ingot was placed on the CSFs and graphite, and a punch was placed on top of the A1070 ingot. The composites were fabricated via the LPI process at $1023 \mathrm{~K}$ in an Argon atmosphere by applying 0.4, 0.6 , and $0.8 \mathrm{MPa}$ of pressure. The volume fraction of CSFs ranged from $7.1 \mathrm{vol} . \%$ to $29.1 \mathrm{vol} . \%$. Figure 1 shows the Manufacturing process of carbon short fiber reinforced Al composite by preformless. Besides, CSF preform of 10 vol.\% reinforced composite fabricated with $\mathrm{SiO}_{2}$ binder (Choi et al. 2017) was used in the comparison of fiber dispersion in composites. The microstructures of the Cu-plated CSFs and $\mathrm{Cu}$ plated CSF/Al matrix composites without preform manufacturing were observed using a scanning electron microscope (SEM, TOPCON SM-520, Japan). The Vickers hardness test was carried out using a load of $3 \mathrm{~kg}_{\mathrm{f}}$ for $10 \mathrm{~s}$. The thermal conductivity of Cu-plated CSF/A1070 composites without preform manufacturing was evaluated by laser flash method thermal constants measuring system $(\mathrm{TC}-9000 \mathrm{H}$, ULVAC-RIKO Inc., Japan) at room temperature. 
Table 1

Solutions used for the different stages in electroless $\mathrm{Cu}$ plating.

\begin{tabular}{|c|c|}
\hline Stage & Solution \\
\hline (a) Sensitization & $12 \mathrm{~g} / \mathrm{I} \mathrm{SnCl}{ }_{2} \otimes 2 \mathrm{H}_{2} \mathrm{O}$ \\
\hline 15 min at room temperature & $40 \mathrm{ml} / \mathrm{l} \mathrm{HCl}$ \\
\hline (b) Activation & $0.2 \mathrm{~g} / \mathrm{I} \mathrm{PdCl} \mathrm{2}_{2} \varangle 2 \mathrm{H}_{2} \mathrm{O}$ \\
\hline $15 \mathrm{~min}$ at room temperature & $2.5 \mathrm{ml} / \mathrm{l} \mathrm{HCl}$ \\
\hline Metallization & $10 \mathrm{~g} / \mathrm{l} \mathrm{CuSO} 4 \llbracket 5 \mathrm{H}_{2} \mathrm{O}$ \\
\hline \multirow[t]{4}{*}{$\mathrm{pH} 12$} & $45 \mathrm{~g} / \mathrm{I}$ EDTA \\
\hline & $20 \mathrm{~g} / \mathrm{l} \mathrm{NaCOOH}$ \\
\hline & $16 \mathrm{ml} / \mathrm{l} \mathrm{HCHO} 36 \%$ \\
\hline & $\mathrm{NaOH}$ for adjusting $\mathrm{pH}$ \\
\hline
\end{tabular}

\section{Results And Discussions}

Microstructures of Cu-plated CSFs and Cu-plated CSF/Al matrix composites. Figure 2 shows the SEM images of as-received CSF and Cu-plated CSFs at different plating times. It was observed that the asreceived CSFs exhibited a clean and smooth surface, as shown in Fig. 2 (a). Figure 2 (b) illustrates that a perfect, uniform Cu-plated layer was acquired over the CSFs after plating for $30 \mathrm{~s}$, which could provide uniform wettability and protection. With increasing plating time, the Cu particles attached on the CSF surface lead to an uneven plating layer as shown by the arrows (Figs. 2 (c) - (e)). Table 2 shows the average $\mathrm{Cu}$ plating layer thickness of CSFs and the density of $\mathrm{Cu}$ - plated CSFs at different plating times. The Cu plating thickness and the density of Cu plated CSFs increased with increasing plating time. The plating thickness varied from 0.81 to $1.12 \mu \mathrm{m}$ and the density of Cu-plated CSFs varied from 2.24 to 2.68 $\mathrm{kg} / \mathrm{m}^{3}$. As the density of liquid aluminum is equal to $2.35 \mathrm{~kg} / \mathrm{m}^{3}$ at $933 \mathrm{~K}$ (Sjostrom et al. 2015), the density of CSFs plated for 30s was similar to that of molten Al, which contributed to fiber dispersion during infiltration. Therefore, the CSFs plating resulting from $30 \mathrm{~s}$ of Cu plating was used for fabricating composites.

Figiure. 2 SEM images of as-received CSF (a), Cu-plated CSF, 30s (b), Cu-plated CSF(60s) (c), Cu-plated CSF, 90s (d) and Cu-plated CSF, 120s (e). 
Table 2

Average Cu-plated thickness and density of Cu-plated CSF by different plating times.

\begin{tabular}{|lll|}
\hline $\begin{array}{l}\text { Plating time } \\
(\mathbf{s})\end{array}$ & $\begin{array}{l}\text { Average thickness } \\
(\boldsymbol{\mu m})\end{array}$ & $\begin{array}{l}\text { Density of Cu-plated CSF } \\
\left(\mathrm{kg} / \mathrm{m}^{\mathbf{3}}\right)\end{array}$ \\
\hline 30 & 0.81 & 2.24 \\
\hline 60 & 1.01 & 2.42 \\
\hline 90 & 1.05 & 2.50 \\
\hline 120 & 1.12 & 2.68 \\
\hline
\end{tabular}

Figure. 4 Microstructures of Cu-plated CSF/A1070 composites without preform manufacturing with different applied pressure under containing 7.1 vol.\% CSF: 0.8 MPa (a), 0.6 MPa (b) and 0.4 MPa (c).

good dispersion of CFs. Figure 5 (a), the CSFs in containing 7.1 vol.\% were more or less uniformly distributed and that some fiber clusters were present in the composites. As the fiber content increased up to $14.3 \mathrm{vol} . \%$, the uniformity of distribution of the CSFs in the composite increased (Fig. 5 (b)). It is difficult to fabricate CSF/AI matrix composite with a CSF content above 20 vol.\% using the conventional fabrication process with CSF preform with $\mathrm{SiO}_{2}$ binder. The Cu-plated CSF/A1070 composites without preform manufacturing containing 29.1 vol.\% CSFs are shown in Fig. 5 (c). Most CSFs were uniformly distributed in the Al matrix which proved that Cu-plated CSFs showed better dispersibility. However, uniformity in the distribution of fibers decreased because of the agglomeration of fibers in the composites due to high fiber volume fraction. Relative frequency distribution of CSFs in the Cu-plated CSF/Al matrix composites fabricated without preform manufacturing with different fiber volume fraction and in CSF preform of 10 vol.\% reinforced Al matrix composite fabricated with $\mathrm{SiO}_{2}$ binder are shown in Fig. 6. In the Cu-plated CSF/Al matrix composites without preform manufacturing in Figs. 6 (a)-(c), CSFs were distributed in each direction and mainly oriented at of $0^{\circ}, 45^{\circ}$, and $90^{\circ}$. It is seen that the CSFs exhibited good dispersibility and flowability in composites.

On one hand, Cu-plated CSFs possessed a density similar to molten Al which can be flowed with molten Al during the infiltration process. On the other hand, the Cu-plated layer was dissolved into the matrix which obviously improved the wettability between the CSFs and Al matrix, endowing CSFs with better dispersibility. Figure 6 (d) shows the relative frequency distribution of fibers mainly oriented at $90^{\circ}$ in composite fabricated with $\mathrm{SiO}_{2}$ binder. This is attributed to the CSFs orientation which was perpendicular to the pressing direction during the preform manufacturing process. As a result, most CSFs were perpendicular to the infiltration direction. Figure 7 shows the image mean free path (IMFP) of the Cuplated CSF/Al matrix composites fabricated without preform manufacturing with different fiber volume fraction and CSF preform reinforced Al matrix composite fabricated with $\mathrm{SiO}_{2}$ binder. The Cu-plated CSF/Al matrix composites containing 7.1, 14.3, and 29.1 vol.\% CSFs showed IMFPs of 163.3, 67.0, and $44.0 \mu \mathrm{m}$, respectively, as shown in Figs. 7 (a)-(c). The mean free path decreased as the volume fraction of 
CSFs increased, causing the microstructure of composites to became much finer as the volume fraction of CSFs increased. The introduction of CSFs can prevent grain growth leading to fine grains in composites. As for the CSF preform of 10 vol.\% reinforced Al matrix composite fabricated with $\mathrm{SiO}_{2}$ binder, the mean free path was $71.9 \mu \mathrm{m}$, as shown in Fig. 7 (d). The mean free path of composite containing 10 vol.\% CSF prefrom fabricated with $\mathrm{SiO}_{2}$ binder was much lower than the predicted value of the composite containing 10 vol.\% CSFs fabricated without preform manufacturing. It was proven that the new fabrication process without preform manufacturing enables the production of composites with refined microstructures and higher reinforcement volume fractions.

Vickers hardness and thermal conductivity of each composite. Figure 8 shows the Vickers hardness of Cu-plated CSF/AI matrix composites without preform manufacturing with different CSF volume fractions. The Vickers hardness of the A1070 matrix was $19.1 \mathrm{Hv}$. The Vickers hardness values of the Cu-plated CSF/Al matrix composites with 7.1, 14.3, and 29.1 vol.\% CSF were $33.9,49.5$, and $54.2 \mathrm{Hv}$,

respectively, as shown in Figs. 8 (a)-(c). The hardness of the composites containing CSFs increases with the increase in CSF content. All composites were harder than the A1070 matrix and dramatically improved by $76 \%, 161 \%$, and $185 \%$. The introduction of CSFs into the Al matrix produces fiber dispersion strengthening in the matrix. In addition, it was reported (Urena et al. 2005) that there is an increase in hardness of the matrix surrounding CSFs due to the dissolving and diffusion of Cu from the surface of fibers, resulting solid solution strengthening in the composites.

Figure 9 shows the thermal conductivity (TC) of the Cu-plated CSF/Al matrix composites without preform manufacturing with different CSF volume fractions, which

were 147.2, 184.1, and $100.1 \mathrm{~W} \cdot \mathrm{m}^{-1} \cdot \mathrm{K}^{-1}$, respectively, as shown in Figs. 9 (a)-(c). It is

seen that the TC first increases with the increase in CSF volume fraction. Cu-plated CSF/Al composite with 14.3 vol.\% CSFs, as seen in Fig. 9 (b), possessed the highest TC among the composites. The high TC was due to the excellent fiber dispersion in the composite, as showng in Fig. 5 (b). However, the composite containing 29.1 vol.\% CSFs exhibited a drop in TC, as shown in Fig. 9 (c). According to the microstructure shown in Fig. 5 (c), CSFs agglomeration was observed due to the high volume fraction of fibers, and imperfect infiltration defects arose from the fiber clusters, causing a decrease in TC.

\section{Conclusions}

A new fabrication process without preform manufacturing was developed for CSF/Al matrix composites. The significant results are summarized as follows:

1. A fairly uniform and continuous Cu layer is plated on CSFs via electroless plating. The fiber dispersion in the Cu-plated CSF/Al matrix composite are also improved, and the defects are minimized. The process can successfully produce composites with up to 29.1 vol.\% CSF without 
preform manufacturing. CSFs are uniformly distributed in the A1070 matrix with little agglomeration and showed better fiber dispersion than the composite fabricated with $\mathrm{SiO}_{2}$ binder.

2. Hardness of composites containing CSFs increases with the increase in the CSF content. The hardness values of the composites containing 7.1, 14.3, and 29.1 vol.\% CSFs were 33.9, 49.5, and, $54.2 \mathrm{Hv}$, which are dramatic improvements of $76 \%, 161 \%$, and $185 \%$, respectively, over that of A1070 matrix.

3. Thermal conductivity of composites containing CSFs increases first then decreases with the increase in the CSF content. The Cu-plated CSF/A1070 composite with 14.3 vol.\% CSF possessed the highest $\mathrm{TC}$ of $184.1 \mathrm{~W} \cdot \mathrm{m}^{-1} \cdot \mathrm{K}^{-1}$ among the composite, which was attributed its excellent fiber dispersion without fiber clusters.

\section{Declarations}

\section{Data availability statement}

The datasets generated and analysed during the current study are available from the corresponding author on reasonable request.

\section{References}

1. Seo, M, K., Park, S, J. Electrochemical characteristics of activated carbon nanofiber electrodes for supercapacitors. Mater. Sci. Eng. B. 164, 106-111,https://doi.org/10.1016/j.mseb.2009.08.005 (2009).

2. Hajjari, E., Divandari, M., Mirhabibi, A, R. The effect of applied pressure on fracture surface and tensile properties of nickel coated continuous carbon fiberreinforced aluminum composites fabricated by squeeze casting. Mater. Des. 31, 2381-2386, https://doi.org/10.1016/j.matdes.2009.11.067 (2010).

3. Meng, X., Choi, Y.B., Matsugi, K., Xu, Z.F., Liu, W.C. Microstructures of carbon fiber and hybrid carbon fiber-carbon nanofiber reinforced aluminum matrix composites by low pressure infiltration process and their properties. Mater. Trans., 59, 1935-1942, https://doi.org/10.2320/matertrans. MAW201808 (2018).

4. Zeng, Q.B. Fabrication of $\mathrm{Al}_{2} \mathrm{O}_{3}$-coated carbon fiber-reinforced Al-matrix composites. J. Appl. Polymer Sci., 70, 177-183, https://doi.org/10.1002/(SICI)1097-4628(19981003)70:1<177::AID-APP17> 3.0.C0;2-4 (1998).

5. Clement, J.P., Rack, H.J., Wu, K, T., Spencer, H.G. Interfacial modification in metal matrix composites by the SOL-GEL process. Mater. Manuf. Process., 19, 17-33, https://doi.org/10.1080/10426919008953226 (2007).

6. Rams, J., Urena, A., Escalera, M.D., Sanchez, M. Electroless nickel coated short carbon fibres in aluminium matrix composites. Compos. Part A Appl. Sci. Manuf. 38, 566-575, https://doi.org/10.1016/j.compositesa.2006.02.010 (2007). 
7. Urena, A., Rams, J., Escalera, M.D., Sanchez, M. Effect of copper electroless coatings on the interaction between a molten Al-Si-Mg alloy and coated short carbon fibres. Compos. Part A Appl. Sci. Manuf. 38, 1947-1956, https://doi.org/10.1016/j.compositesa.2007.02.005 (2007).

8. Choi, Y.B., Matsugi, K., Sasaki, G., Yanagisawa, O. Analysis of manufacturing processes for metal fiber reinforced aluminum alloy composite fabricated by low-pressure casting. Mater. Trans., 47, 1227-1231, https://doi.org/10.2320/matertrans.47.1227 (2006).

9. Choi, Y.B., Matsugi, K., Sasaki, G., Yanagisawa, O. Analysis of manufacturing processes for metal fiber reinforced aluminum alloy composite fabricated by low-pressure casting. Mater. Trans., 47, 1227-1231, https://doi.org/10.2320/matertrans.47.1227 (2006).

10. Choi, Y.B., Kataoka, Y., Xu, Z.F., Matsugi, K., Sasaki, G. Manufacturing process of carbon-alumina short fiber hybrid reinforced aluminum matrix composites by low pressure casting. Mater. Trans., 58, 10971099, https://doi.org/10.2320/matertrans.M2017075 (2017).

11. Sjostrom, T., and Daligault, J. Ionic and electronic transport properties in dense plasmas by orbitalfree density functional theory, Phys. Rev. E. 92, 1-8, 10.1103/PhysRevE.92.063304 (2015).

12. Urena, A., Rams, J., Escalera, M.D., Sanchez, M. Characterization of interfacial mechanical properties in carbon fibre/aluminium matrix composites by the nanoindentation technique. Compos. Sci. Technol. 65, 2025-2038, https://doi.org/10.1016/j.compscitech.2005.04.013 (2005).

\section{Figures}




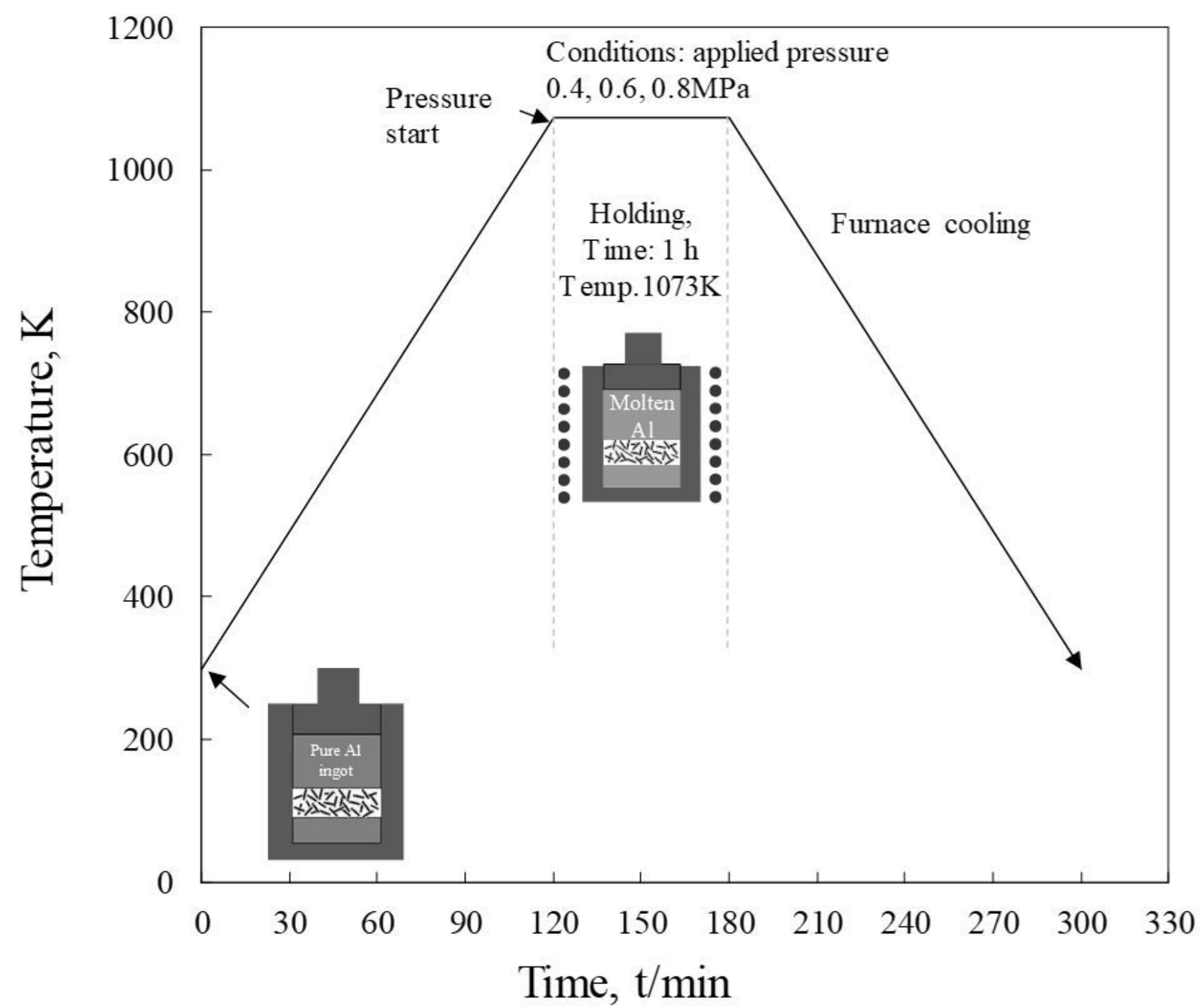

Figure 1

Manufacturing process of carbon short fiber reinforced Al composite by preformless. 
(a)

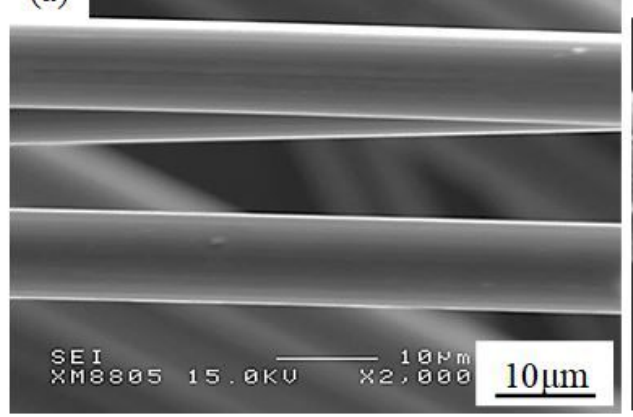

\section{(b)}

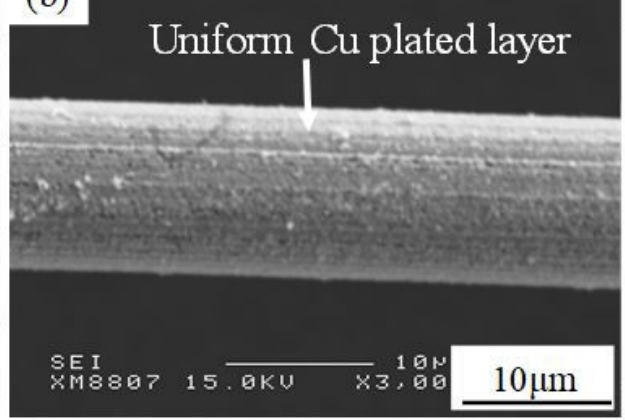

(d)

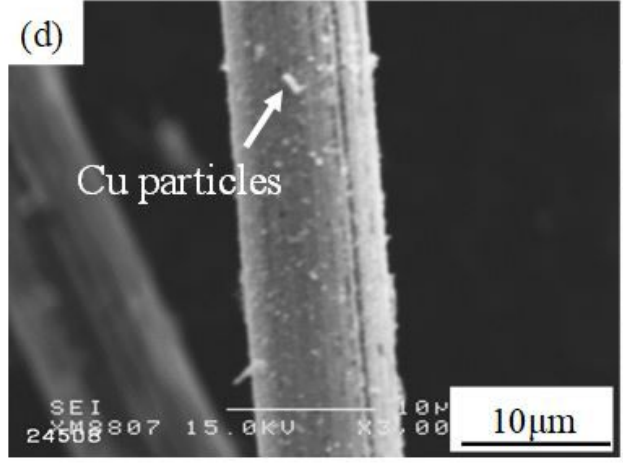

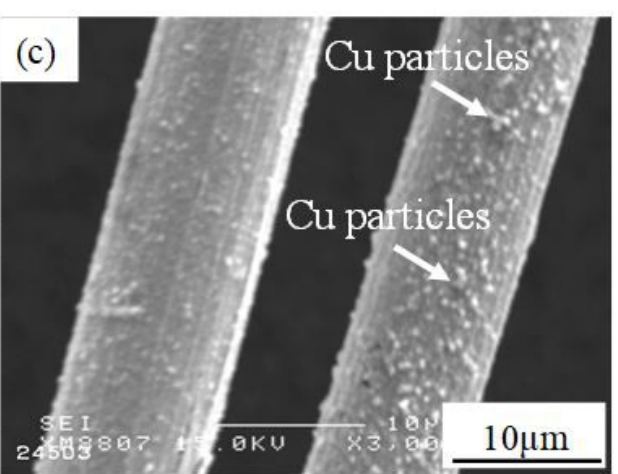

(e)

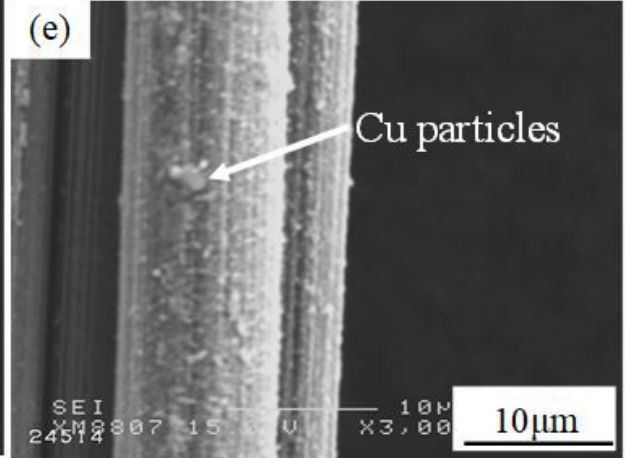

Figure 2

SEM images of as-received CSF (a), Cu-plated CSF, 30s (b), Cu-plated CSF (60s) (c), Cu-plated CSF, 90s (d) and Cu-plated CSF, 120s (e).
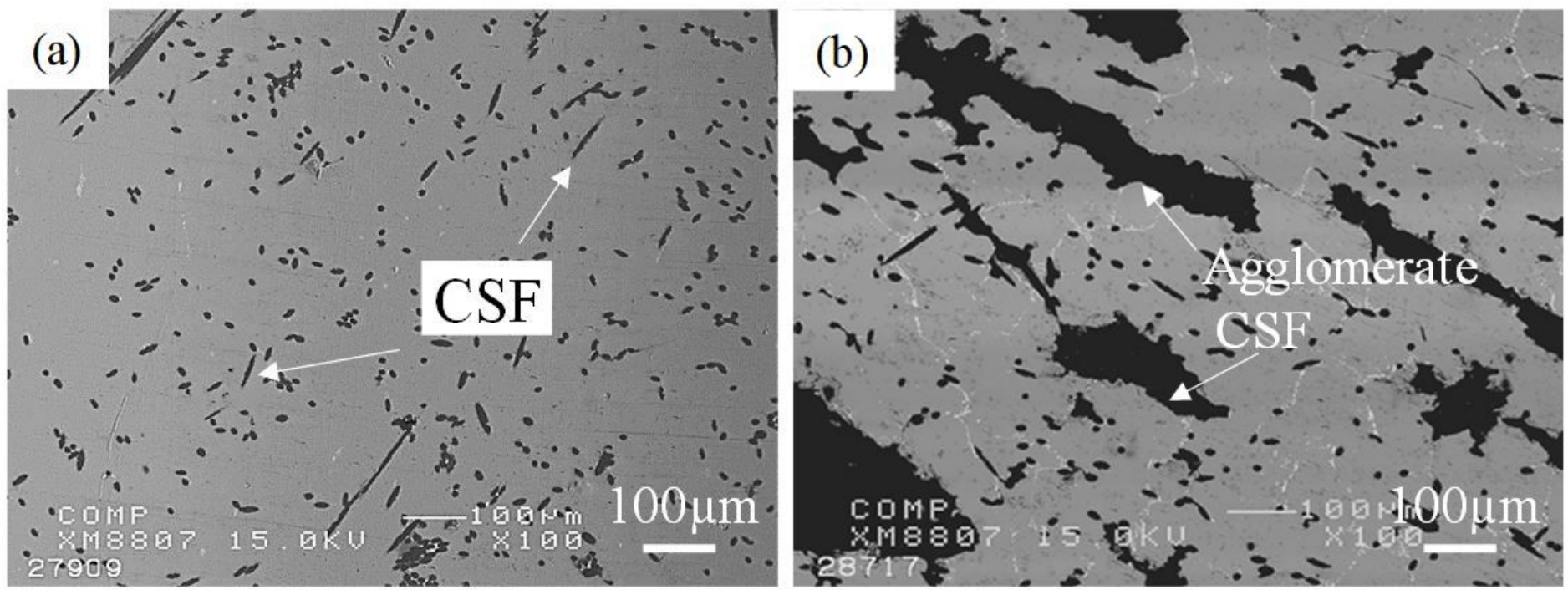

\section{Figure 3}

Microstructures of Cu-plated CSF and as received CSF reinforced A1070 composites without preform manufacturing under pressure of 0.8 MPa: Cu-plated CSF (a), as-received CSF without Cu plating (b). 

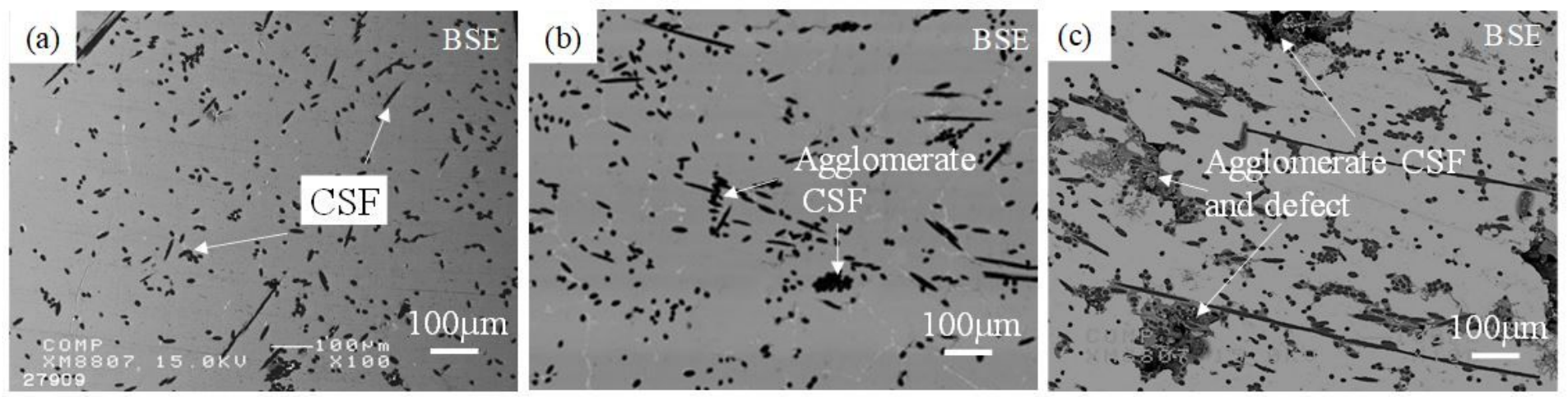

\section{Figure 4}

Microstructures of Cu-plated CSF/A1070 composites without preform manufacturing with different applied pressure under containing 7.1 vol.\% CSF: 0.8 MPa (a), 0.6 MPa (b) and 0.4 MPa (c).
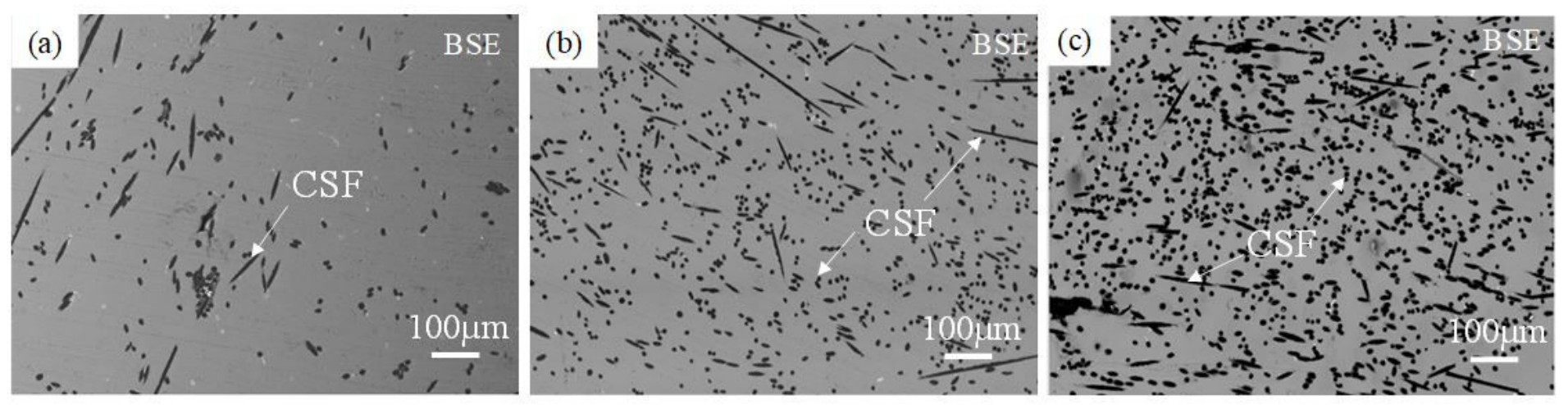

\section{Figure 5}

Microstructures of Cu-plated CSF/A1070 composites without preform manufacturing with different volume fraction of CSF under pressure of $0.8 \mathrm{MPa} 7.1$ (a), 14.3 (b) and 29.1 vol.\% (c). 

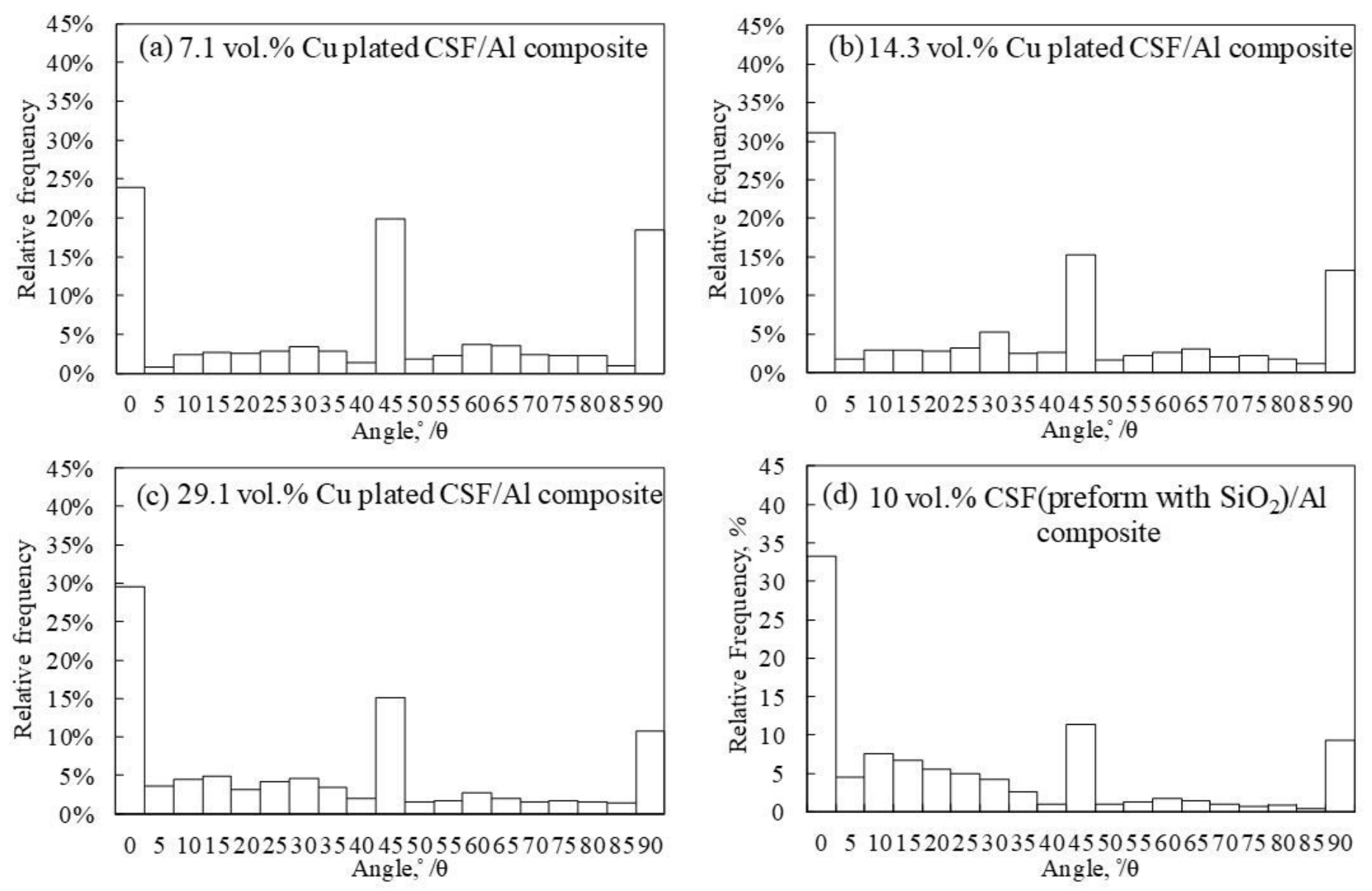

\section{Figure 6}

Relative frequency distribution of CSFs in composites view of cross section: Cu- plated CSF (7.1 vol.\%)/Al composite (a), Cu-plated CSF (14.3 vol.\%)/Al composite (b), Cu-plated CSF (29.1 vol.\%)/Al composite (c) and CSF prefrom of 10 vol.\% with SiO2 binder /Al composite (d). 


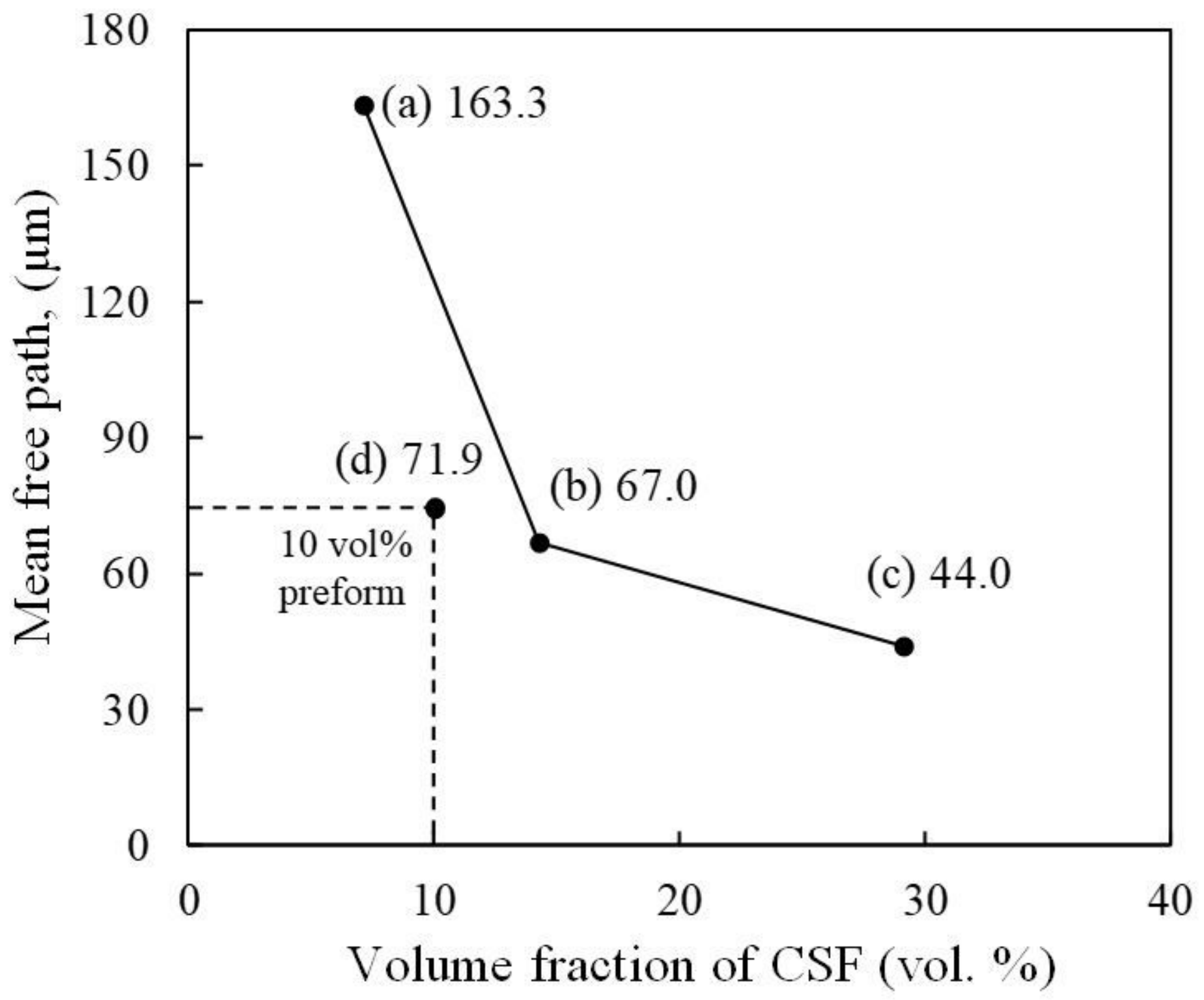

Figure 7

Image mean free path (IMFP) of CSF/Al composites with different volume fraction of CSF: Cu-plated CSF (7.1 vol.\%)/Al composite (a), Cu-plated CSF (14.3 vol.\%)/Al composite (b), Cu-plated CSF (29.1 vol.\%)/Al composite (c) and CSF preform of 10 vol.\% with SiO2 binder /Al composite (d). 


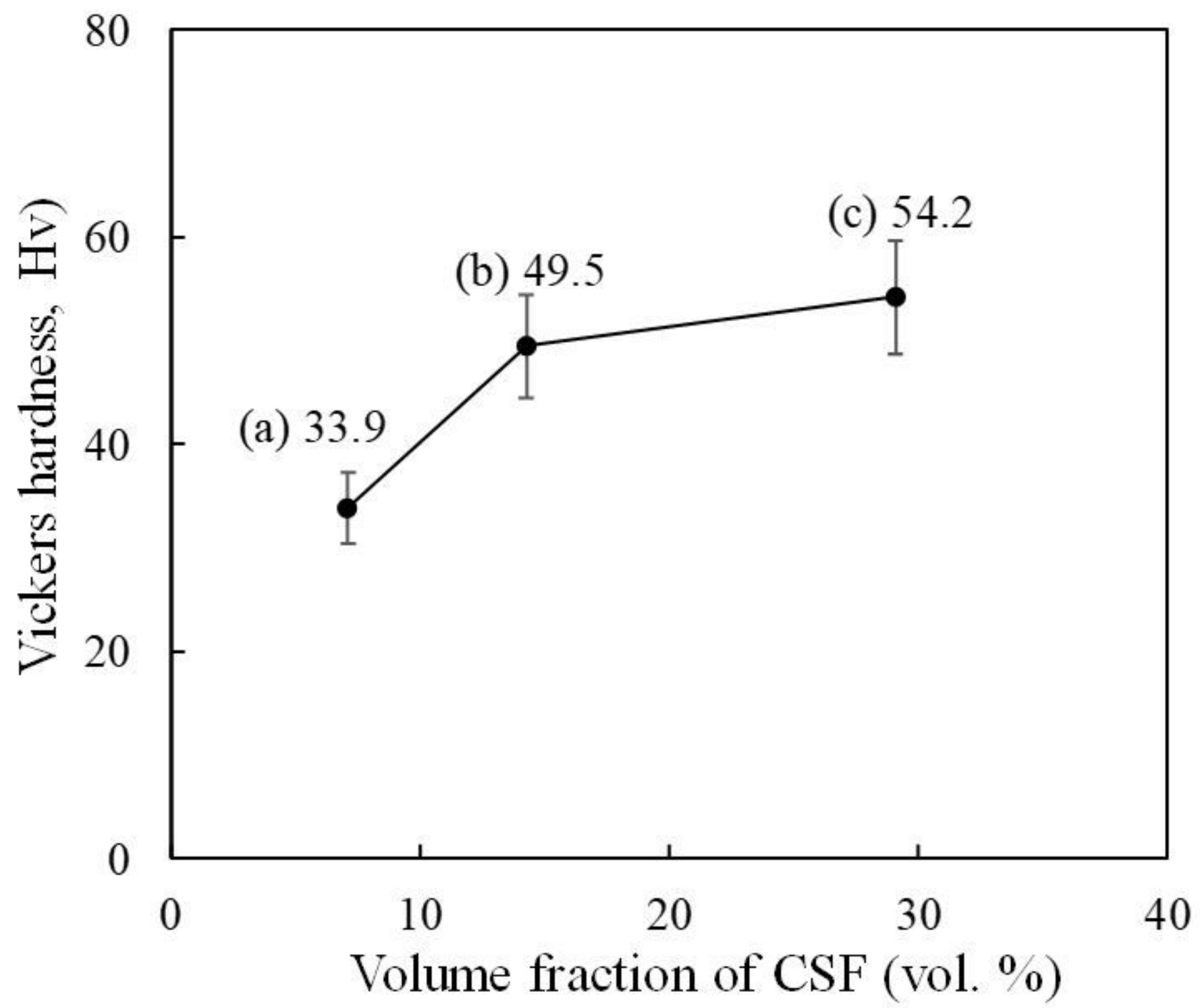

Figure 8

Vickers hardness of Cu-plated CSF/Al composites by different volume fraction: Cu-plated CSF (7.1 vol.\%)/Al composite(a), Cu-plated CSF (14.3 vol.\%)/Al composite (b) and Cu-plated CSF (29.1 vol.\%)/Al composite (c). 


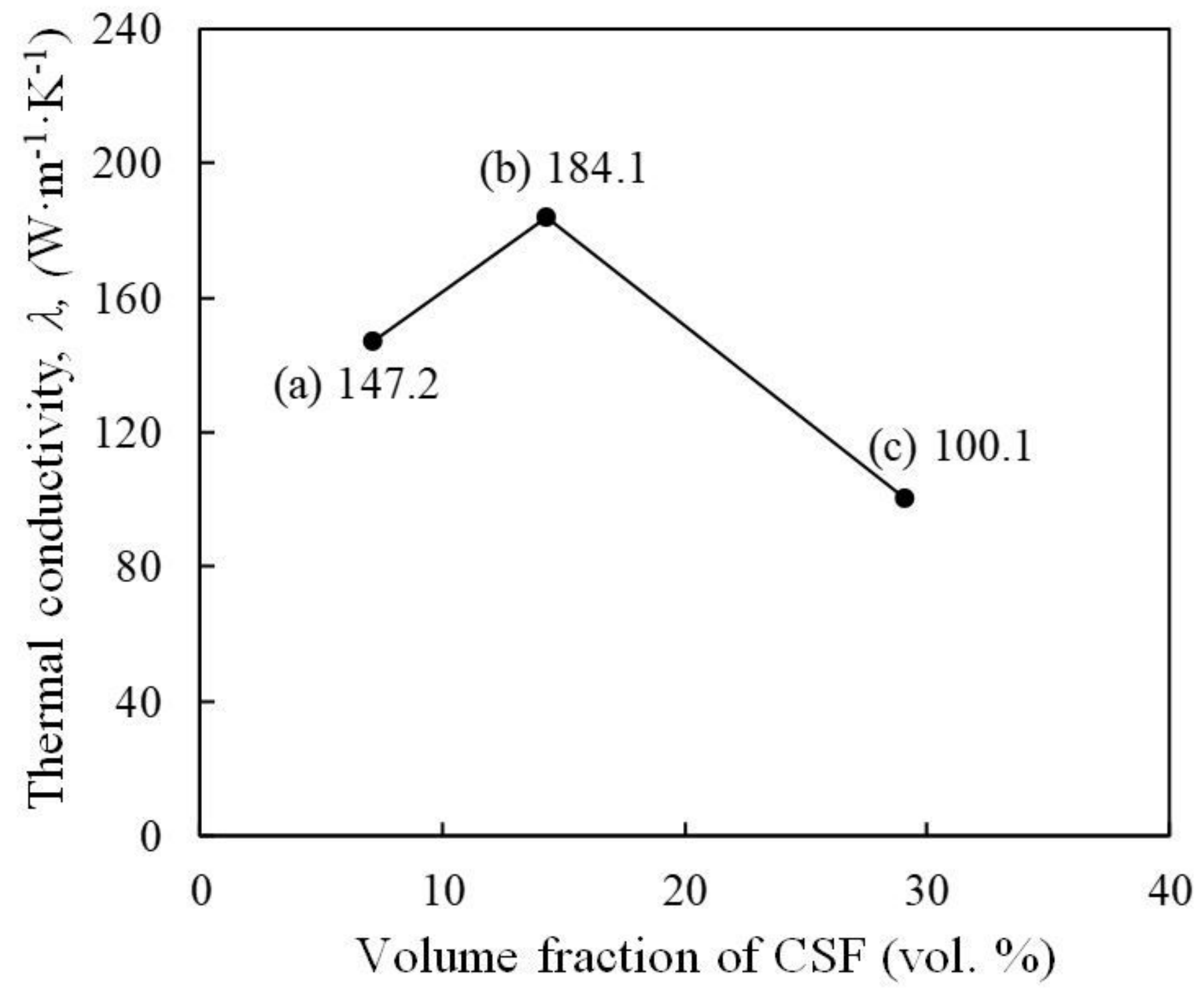

Figure 9

Thermal conductivity of Cu-plated CSF/Al composites by different volume fraction: Cu-plated CSF (7.1 vol.\%)/Al composite (a), Cu-plated CSF (14.3 vol.\%)/Al composite (b) and Cu-plated CSF (29.1 vol.\%)/Al composite (c). 